\title{
Comparison of the Efficacy of Different Therapeutic Regimen in the Management of Glaucoma in Dogs
}

\author{
T. C. Soundarya ${ }^{1 *}$, M. A. Kshama ${ }^{2}$, Suguna Rao $^{3}$ and V. Mahesh ${ }^{4}$ \\ ${ }^{1}$ Department of Veterinary Medicine, Veterinary College, KVAFSU, Bangalore-560024, India \\ ${ }^{3}$ Department of Pathology Veterinary College, KVAFSU, Bangalore-560024, India \\ ${ }^{4}$ Department of Surgery Veterinary College, KVAFSU, Bangalore-560024, India \\ *Corresponding author
}

\section{A B S T R A C T}

Keywords

Timolol,

Dorzolamide and

Timolol fixed

combination,

Latanoprost and

Timolol fixed

combination,

glaucoma.

Article Info

Accepted:

20 January 2020

Available Online:

10 February 2020

\begin{abstract}
Eighteen dogs presented to the Veterinary College Hospital, Bangalore exhibiting clinical signs of glaucoma and IOP more than $25 \mathrm{mmHg}$ were selected. These dogs were divided into 3 groups of 6 animals each and were subjected to therapeutic management of glaucoma. Group I was treated with Timolol Maleate ophthalmic solution, 1 drop, BID, Group II was treated with Dorzolamide and Timolol, 1 drop, BID and Group III was treated with Latanoprost and Timolol, 1 drop, BID. The duration of therapy was for 2 months and the dogs were monitored every once in 15 days i.e., day 0 , day 15 , day 30 , day 45 and day 60 following initiation of therapy. It was found that Group III dogs treated with Latanoprost and Timolol combination responded better than the other two groups followed closely by Group II dogs treated with Dorzolamide and Timolol combination whereas monotherapy with Timolol was not very effective.
\end{abstract}

\section{Introduction}

There are several disorders of the eye that the dog needs to be protected from which includes conjunctivitis, corneal opacity, cataract, glaucoma, traumatic injuries, corneal ulceration, keratoconjunctivitissicca, uveitis, keratitis and tumours. Of these, Glaucoma is one of the major causes of irreversible blindness. Thus early diagnosis and treatment of Glaucoma plays a vital role in protecting the dog's visual system.

Elevated intraocular pressure (IOP) is the most significant risk factor for developing glaucoma. The term 'ocular hypertension' is used for cases having constantly raised intraocular pressure (IOP) without any associated optic nerve damage. Conversely, the term 'normal' or 'low tension glaucoma' 
is suggested for the typical visual field defects when associated with a normal or low IOP. Most medical treatments for glaucoma are designed to lower and/or control intraocular pressure, which can damage the optic nerve that transmits visual information to the brain. Anti-glaucoma drugs work by reducing aqueous humour formation or by increasing its outflow.

Taking into consideration the gradually increasing incidence of ocular diseases in dogs in general and glaucoma in particular and the difficulty encountered in its management, the present study was undertaken with the objective to compare the efficacy of different therapeutic regimen in the treatment of Glaucoma in dogs.

\section{Materials and Methods}

Dogs presented to the Veterinary College Hospital, Bangalore exhibiting symptoms of ocular disease were selected for further studies. Detailed examination of all the clinical cases with ocular problems was performed and findings were recorded.

Dogs with clinical signs such as enlargement of the eyeball (bupthalmos), episcleritis, blepherospasms, cloudy appearance of the cornea, dialated pupil, absence of pupillary light reflex, visual impairment or loss of vision were tentatively diagnosed as glaucoma. Intraocular pressure was measured with the help of perkins applanation tonometer. Dogs with intraocular pressure of more than $25 \mathrm{mmHg}$ were diagnosed as glaucoma. Eighteen dogs with glaucoma were selected based on clinical signs and IOP measurement and divided into three groups of six animals each and were subjected to therapeutic management of glaucoma. Dogs of Group I was treated with Timolol Maleate ophthalmic solution, 1 drop, BID, Dogs of Group II was treated with Dorzolamide and
Timolol, 1 drop, BID and Dogs of Group III was treated with Latanoprost and Timolol, 1 drop, BID. The duration of therapy was for two months and the dogs were monitored every once in 15 days i.e., day 0 , day 15, day 30, day 45 and day 60 following initiation of therapy. The improvement in the condition was assessed based on reduction in IOP and resolution of clinical signs. Scores were allotted depending on response to therapy as excellent (5), good (4), moderate (3), marginal (2) and poor (1) based on resolution of clinical signs and recovery as elaborated in Table 1 and the different per cent occurrence of different clinical signs are depicted in Table 2.

\section{Results and Discussion}

\section{Group I - treatment with timolol}

The mean intraocular pressure (IOP) on day $0,15,30,45$ and 60 in dogs treated with Timolol were $34.41 \pm 1.46 \mathrm{mmHg}, 33.83 \pm$ $1.16 \mathrm{mmHg}, 32.41 \pm 1.16 \mathrm{mmHg}, 32.41 \pm$ $1.02 \mathrm{mmHg}, 31.66 \pm 0.75 \mathrm{mmHg}$ and $29.33 \pm$ $0.40 \mathrm{mmHg}$ respectively. The mean IOP reduced non significantly from day 0 to day 30 and subsequently IOP reduced significantly $(\mathrm{P}<0.05)$ from day 45 to day 60 from $31.66 \pm 0.75 \mathrm{mmHg}$ to $29.33 \pm 0.40 \mathrm{~mm}$ $\mathrm{Hg}$ in this group (Table 3, Fig 3 and 4).

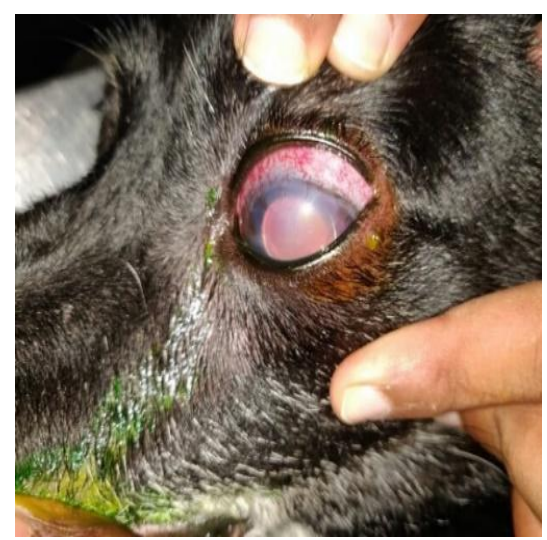

Fig.3 Group I dog on day 1 prior to initiation treatment 


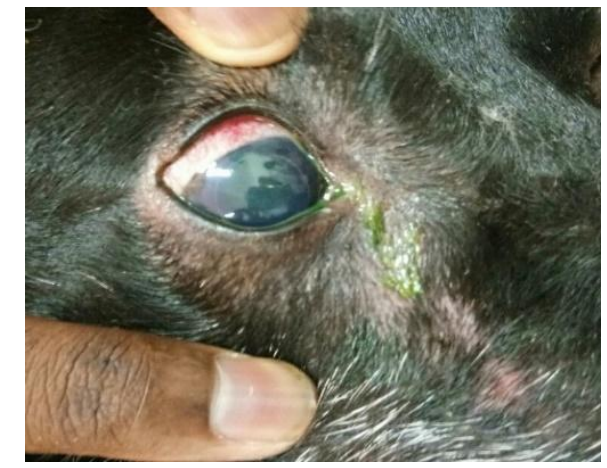

Fig.4 Group I dog on day 60 following therapy

Based on the resolution of clinical signs Mean \pm SD score of dogs of Group II on day $15,30,45$ and 60 were $1.00 \pm 0.00(20 \%)$, $1.33 \pm 0.28(26.6 \%), 2.16 \pm 0.28(43.2 \%)$ and $2.33 \pm 0.28(46.6 \%)$ respectively. The results are depicted in Table 4.

\section{Treatment with dorzolamide and timolol - group II}

The mean intraocular pressure (IOP) on day $0,15,30,45$ and 60 in dogs treated with combination of Dorzolamide - Timolol were $34.41 \pm 1.20 \mathrm{mmHg}, 31.50 \pm 1.84 \mathrm{mmHg}$, $29.00 \pm 0.70 \mathrm{mmHg}, 25.83 \pm 0.68 \mathrm{mmHg}$ and $24.50 \pm 0.44 \mathrm{mmHg}$ respectively. The mean IOP reduced significantly $(\mathrm{P}<0.05)$ from day 0 to day 60 from $34.41 \pm 1.20 \mathrm{mmHg}$ to 24.50 $\pm 0.44 \mathrm{mmHg}$ in this group (Table 3, Fig 5 and 6).

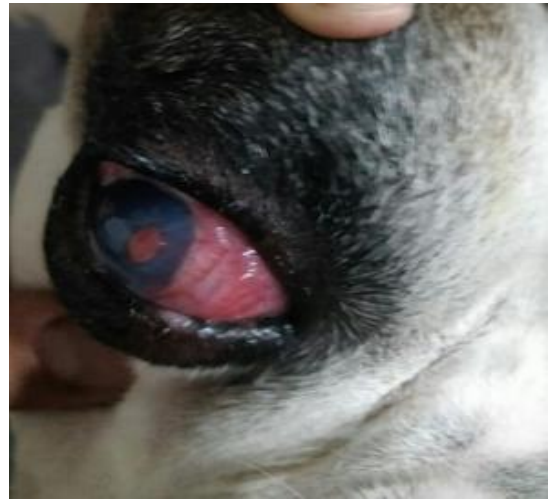

Fig.5 Group II dog on day 1 prior to initiation of treatment

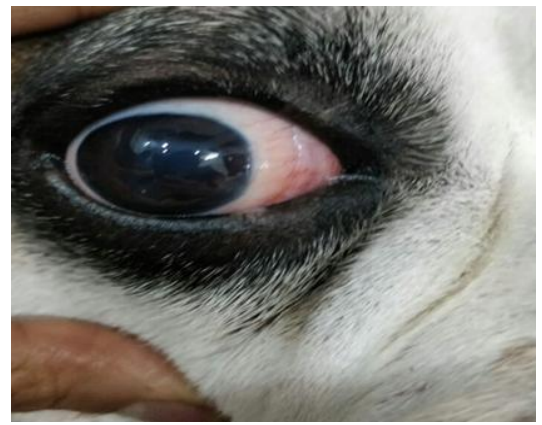

Fig.6 Group II dog on day60 following therapy

Based on the resolution of clinical signs Mean \pm SD score of dogs of Group II on day $15,30,45$ and 60 were $1.16 \pm 0.28(23.2 \%)$, $2.16 \pm 0.28(43.2 \%), 2.50 \pm 0.50(50 \%)$ and $3.50 \pm 0.50(70 \%)$ respectively. The results are depicted in (Table 4).

\section{Treatment with latanoprost and timolol - group III}

The mean intraocular pressure (IOP) onday 0 , $15,30,45$ and 60 in dogs treated with a combination of Latanoprost - Timolol were $33.33 \pm 2.11 \mathrm{mmHg}, 31.25 \pm 1.99 \mathrm{mmHg}$, $27.66 \pm 0.68 \mathrm{mmHg}, 25.16 \pm 1.12 \mathrm{mmHg}$ and $23.66 \pm 0.93 \mathrm{mmHg}$ respectively. The mean IOP reduced non significantly from day 0 to day 15, further mean IOP reduced significantly $(\mathrm{P}<0.05)$ from day 30 to day 45 from $27.66 \pm 0.68$ to $25.16 \pm 1.12$ and day 45 to day 60 from $25.16 \pm 1.12 \mathrm{mmHg}$ to $23.66 \pm$ $0.93 \mathrm{mmHg}$ respectively in this group (Table 3, Fig7 and 8).

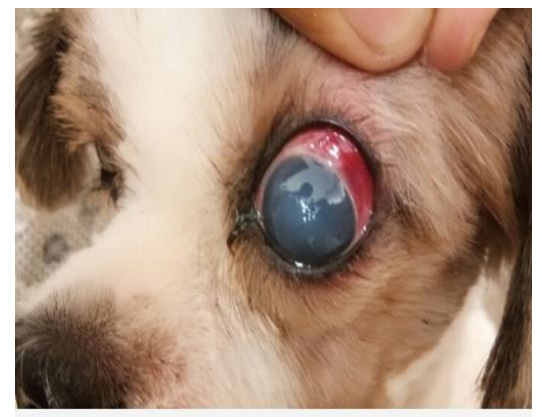

Fig.7 Group III dog on day 1 prior to initiation of treatment 


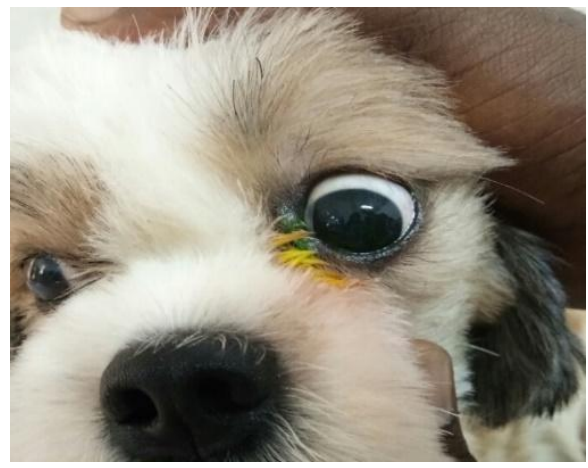

Fig.8 Group III dog on day 60 following therapy

Based on the resolution of clinical signs Mean \pm SD score of dogs of Group III on day $15,30,45$ and 60 were $1.16 \pm 0.28(23.2 \%)$,
$2.16 \pm 0.28(43.2 \%), 2.50 \pm 0.50(50 \%)$ and $3.50 \pm 0.50(73.2 \%)$ respectively. The results are depicted in (Table 4).

\section{Comparison between groups}

\section{Intraocular pressure measurement}

On day 0, mean IOP of Group I, Group II and Group III on day 0 was $34.41 \pm 1.46 \mathrm{mmHg}$, $34.41 \pm 1.20 \mathrm{~mm} \mathrm{Hg}$ and $33.33 \pm 2.11 \mathrm{mmHg}$ respectively. There was no significant difference between the 3 groups (Table 3, Fig $1)$.

Table.1 Score card used for the evaluation of glaucoma based on clinical signs in dogs

\begin{tabular}{|c|c|c|c|}
\hline Sl. No. & Criteria for allocation of scores & Scores & Grading \\
\hline $\mathbf{1}$ & Complete resolution of clinical signs & 5 & Excellent \\
\hline $\mathbf{2}$ & $75 \%$ reduction of clinical signs & 4 & Good \\
\hline $\mathbf{3}$ & $50 \%$ reduction of clinical signs & 3 & Moderate \\
\hline $\mathbf{4}$ & $25 \%$ reduction of clinical signs & 2 & Marginal \\
\hline $\mathbf{5}$ & No change / worsening of the condition & 1 & Poor \\
\hline
\end{tabular}

Table.2 Clinical signs observed in glaucoma in dogs selected for therapeutic trials during the study $(\mathrm{n}=18)$

\begin{tabular}{|c|c|c|}
\hline Clinical signs & No. of cases & \% occurrence \\
\hline Absence of pupillary light reflex & 18 & 100 \\
\hline Injected episcleral vessels & 18 & 100 \\
\hline Bupthalmos & 05 & 27.7 \\
\hline Cloudy cornea & 08 & 44.4 \\
\hline Pain & 11 & 61 \\
\hline Dilated pupil & 07 & 38.8 \\
\hline Vision problems & 18 & 100 \\
\hline Tearing & 06 & 33.3 \\
\hline Blepherospasms & 0 & 0 \\
\hline Weak Menace and Dazzle reflex & 18 & 100 \\
\hline
\end{tabular}


Table.3 Mean IOP between and within treatment groups

\begin{tabular}{|c|c|c|c|c|c|}
\hline $\begin{array}{c}\text { Antiglaucoma } \\
\text { drugs }\end{array}$ & Day 0 & Day 15 & Day 30 & Day 45 & Day 60 \\
\hline $\begin{array}{c}\text { Timolol } \\
\text { Dorzolamide- } \\
\text { Timolol }\end{array}$ & $34.41 \pm 1.46^{\mathrm{Aa}}$ & $33.83 \pm 1.16^{\mathrm{Aa}}$ & $32.41 \pm 1.02^{\mathrm{Aa}}$ & $31.66 \pm 0.75^{\mathrm{Ab}}$ & $29.33 \pm 0.40^{\mathrm{Ac}}$ \\
\hline $\begin{array}{c}\text { Latanoprost- } \\
\text { Timolol }\end{array}$ & $33.33 \pm 2.10^{\mathrm{Aa}}$ & $31.50 \pm 1.84^{\mathrm{Aa}}$ & $29.00 \pm 0.70^{\mathrm{Bc}}$ & $25.83 \pm 0.68^{\mathrm{Bd}}$ & $24.50 \pm 0.44^{\mathrm{Be}}$ \\
\hline
\end{tabular}

Figures bearing different superscripts within a row and column differ significantly $(\mathrm{P}<0.05)$ NS = Non significant

Table.4 Mean \pm SD of scores as response to therapy based on resolution of clinical signs in the 3 groups of dogs with glaucoma

\begin{tabular}{|c|c|c|c|}
\hline $\begin{array}{l}\text { Days of } \\
\text { treatment }\end{array}$ & $\begin{array}{l}\text { Group } 1 \\
\text { response) }\end{array}$ & $\begin{array}{l}\text { Group } 2 \\
\text { response) }\end{array}$ & Group 3 (\% response) \\
\hline Day 15 & $1.00 \pm 0.00^{\mathrm{Aa}}(20)$ & $1.16 \pm 0.28^{\mathrm{Aa}}$ & $1.16 \pm 0.28^{\mathrm{Aa}}$ \\
\hline Day 30 & $1.33 \pm 0.28^{\mathrm{Aa}}(26.6)$ & $2.16 \pm 0.28^{\mathrm{Aa}}(43.2)$ & $2.16 \pm 0.28^{\mathrm{Aa}}$ \\
\hline Day 45 & $2.16 \pm 0.28^{\mathrm{Ab}}$ & $2.50 \pm 0.50^{\mathrm{Ab}}$ & $2.50 \pm 0.50^{\mathrm{Ab}}$ \\
\hline Day 60 & $2.33 \pm 0.28^{\mathrm{Ac}}(46.6)$ & $3.50 \pm 0.50^{\mathrm{Bc}}$ & $3.66 \pm 0.57^{\mathrm{Bc}}$ \\
\hline
\end{tabular}

Group 1 - Conventional therapy with Timolol

Group 2 - Conventional therapy with Dorzolamide - Timolol

Group 3 - Conventional therapy with Latanoprost - Timolol

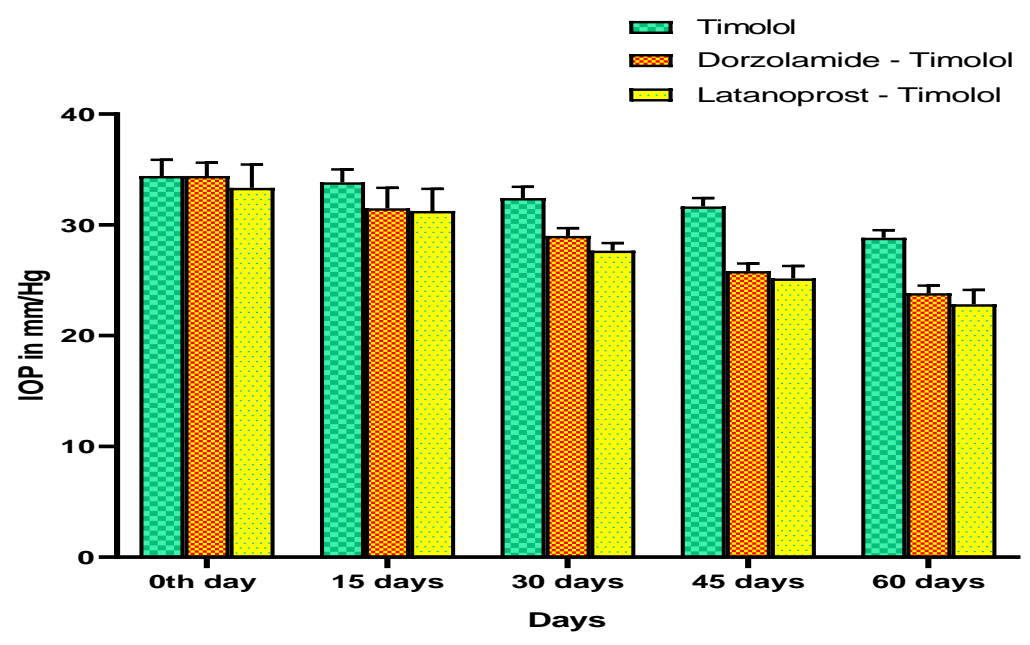

Figure.1 Mean IOP between and within treatment groups 


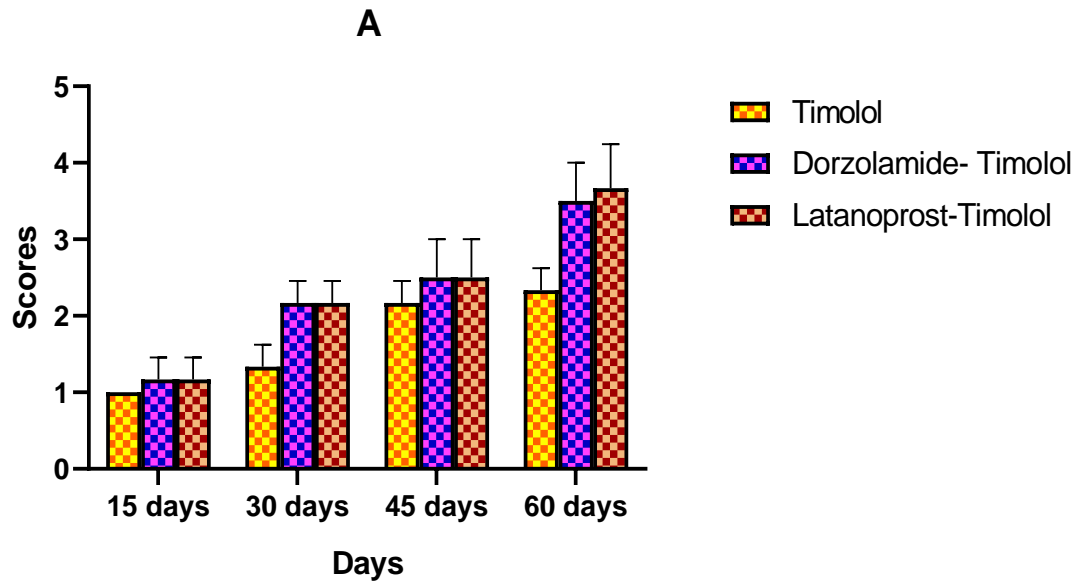

Figure. 2 Mean \pm SD of scores as response to therapy based on resolution of clinical signs in the 3 groups of dogs with glaucoma

At the end of the therapy i.e.,on day 60, mean IOP of Group I, Group II and Group III was $29.33 \pm 0.40 \mathrm{mmHg}, 24.50 \pm 0.44 \mathrm{mmHg}$ and $23.66 \pm 0.93 \mathrm{mmHg}$ respectively. Significant difference $(\mathrm{P}<0.05)$ was found between Group I (Timolol) $(29.33 \pm 0.40 \mathrm{mmHg})$ and Group II (Dorzolamide - Timolol) $(24.50 \pm$ $0.44 \mathrm{mmHg}$ ). Similarly significant reduction in IOP $(\mathrm{P}<0.05)$ was found between Group I (Timolol) (29.33 $\pm 0.40 \mathrm{mmHg})$ and Group III (Latanoprost - Timolol) (23.66 \pm 0.93 $\mathrm{mmHg}$ ).

There was no significant difference in reduction of IOP between Group II (Dorzlamide- Timolol) $(24.50 \pm 0.44 \mathrm{mmHg})$ and Group III (Latanoprost - Timolol ) (23.66 $\pm 0.93 \mathrm{mmHg}$ ). However there was better response to therapy in Group III dogs as assessed by IOP reduction and alleviation of clinical signs. The results are depicted in the Table 3, Table 4, Fig 1 to Fig 8.

According to Varma et al., (2008) the overall goal of medical therapy in patients with glaucoma or ocular hypertension is to reduce IOP levels to minimize disease progression. The mean IOP between the groups observed in the present study varied from $33.33 \pm 2.11$ $\mathrm{mmHg}$ to $34.41 \pm 1.46 \mathrm{mmHg}$ on day 0 to
$23.66 \pm 0.93 \mathrm{mmHg}$ to $29.33 \pm 0.40 \mathrm{mmHg}$ on day 60 following therapy. Gelatt and Mackay (1998) have reported that mean normal value for IOP estimated using applanation tonometry is $19.2 \pm 5.5 \mathrm{mmHg}$. The mean clinical response between the groups varied from $46.6 \%$ in group I to $73.2 \%$ in group II after day 60 of therapy.

In the present study it was observed that, the reduction in the IOP of Group II and Group III dogs was greater than that of Group I. Further it was observed that, IOP lowering effect of Group II and Group III was almost similar. A statistically significant difference was found between Group I and Group II and Group I and Group III whereas Group II and Group III had statistically similar ocular hypotensive effect.

The results of the present study are in accordance with the findings of Shin et al., (2004), Siesky et al., (2006) and Eren et al., (2012). The details of which are elaborated below.

Shin et al., (2004) have compared the efficacy of Latanoprost and Timolol fixed combination (LTFC) and Dorzolamide and Timolol fixed combination (DTFC). They noted that LTFC 
was slightly more effective than that of DTFC in reducing mean diurnal IOP at month 3 with a mean percentage reduction of $33.5 \%$ in the LTFC group and $30.3 \%$ in DTFC treated patient.

Eren et al., (2012) after a study on human patients reported that mean IOP and peak IOP were lower with Latanoprost and Timolol fixed combination (LTFC) than with Dorzolamide and Timolol fixed combination(DTFC) in patients with primary open angle glaucoma. They reported that the mean baseline IOP was $25.09 \pm 2.8 \mathrm{mmHg}$. After the treatment period, the mean diurnal IOP was statistically lower with LTFC than with DTFC.

Siesky et al., (2006) have studied the effects of DTFC and LTFC. They reported that, both therapies were effective at lowering IOP in patients treated with primary open angle glaucoma (POAG). They found that patients treated with LTFC (13.9\%) and DTFC (12.2\%) had a statistically similar ocular hypotensive effect.

The results of present study is contrary to the observations of Parmaksiz et al., (2006) who have reported that Dorzolamide and Timolol fixed combination (DTFC) was more effective in reducing IOP than Latanoprost and Travaprost.

Cvenkel et al., (2008) following a study with human glaucoma patients reported that 32 patients with POAG or ocular hypertension had a mean diurnal IOP of $19.5 \mathrm{mmHg}$ for DTFC and $18.9 \mathrm{mmHg}$ for LTFC $(\mathrm{P}>0.05)$ with no significant difference found between DTFC and LTFC at any point of time. The mean IOP reduction from the baseline was $21.6 \pm 3.8 \mathrm{mmHg}$ to $19.5 \pm 3.2 \mathrm{mmHg}$ for DTFC and $20.7 \pm 3.8 \mathrm{mmHg}$ to $18.9 \pm 3.4$ $\mathrm{mmHg}$ for LTFC respectively.
Thus it can be concluded that Latanoprost and Timolol combination therapy was a more effective therapy for dogs with glaucoma with Dorzolamide and Timolol combination therapy showing almost similar but slightly lower efficacy. Monotherapy with Timolol however was not very effective. However the overall clinical improvement observed with medical management was only moderate $(73.2 \%)$. This could be due to the fact that glaucoma could have been closed angle glaucoma and no effort was made in the present study to classify it based on gonioscopy.

Gelatt and Mackay (2004) have reported that most common type of primary glaucoma in dogs is the angle closure glaucoma. They have further reported the prevalence of secondary glaucoma due to cataract, lens luxation, uveitis and neoplasia to be common in dogs. Further, Gould and McLellan (2014) reported that anti-glaucoma drugs have been developed for treatment of human open-angle glaucoma and these are poorly effective as a treatment for canine or feline closed angle glaucoma.

\section{References}

Cvenkel, B., Stewart, J. A., Nelson, L. A. and Stewart, W. C.2008. Dorzolamide/ timolol fixed combination versus latanoprost/timolol fixed combination in patients with primary open-angle glaucoma or ocular hypertension. Curr Eye Res.33(2): 163-168.

Eren, M. H., Gungel, H., Altan, C., Pasaoglu, I. B. and Sabanci, S. 2012. Comparison of dorzolamide/timolol and latanoprost/ timolol fixed combinations on diurnal intraocular pressure control in primary open-angle glaucoma. J. Ocul. Pharmacol. Th.28(4): 381-386.

Gelatt, K. N. and Mackay, E. O., 2004. Secondary glaucomas in the $\operatorname{dog}$ in 
North America. Vet.Opthalmol. 7(4): 245-259.

Gould, D and Mc Lellan, G. J. 2004. BSAVA manual of canine and feline ophthalmology., (Ed. 3). 55-58.

Parmaksiz, S., Yuksel, N., Karabas, V. L., Ozkan, B., Demirci, G. and Caglar, Y. 2006.A comparison of travoprost, latanoprost, and the fixed combination of dorzolamide and timolol in patients with pseudoexfoliative glaucoma. Eur J Ophthalmol.16(1): 73-80.

Shin, D., Feldman, R. M. and Sheu, W. P. 2004. Efficacy and safety of the fixed combinations latanoprost/ timolol versus dorzolamide/timolol in patients with elevated intraocular pressure. Opthalmology, 111(2): 276-282.

Siesky, B., Harris, A., and Sines, D. 2006. A comparative analysis of the effects of the fixed combination of timolol on hemodynamics and visual function in patients with primary open angle glaucoma. J. Ocul. Pharmacol. Ther,22: 353-361.

Varma, R., Peeples, P., Walt, J. G. and Bramley, T. J. 2008. Disease progression and the need for neuroprotection in glaucoma management. Am. J. Manag. Care.14: 15-19.

\section{How to cite this article:}

Soundarya. T. C, M. A. Kshama, Suguna Rao and Mahesh. V. 2020. Comparison of the Efficacy of Different Therapeutic Regimen in the Management of Glaucoma in Dogs. Int.J.Curr.Microbiol.App.Sci. 9(02): 2779-2786. doi: https://doi.org/10.20546/ijcmas.2020.902.316 